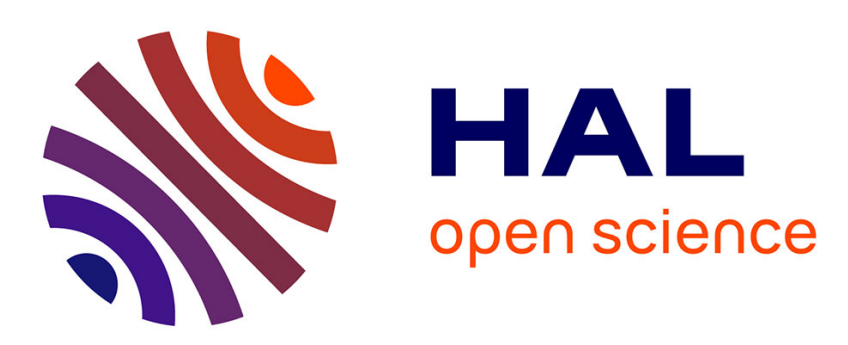

\title{
Eshelby-Kröner viscoelastic self-consistent model: Multi-scale behavior of polymer composites under creep loading
}

\author{
A. Yousfi, Sylvain Fréour, Frédéric Jacquemin
}

\section{- To cite this version:}

A. Yousfi, Sylvain Fréour, Frédéric Jacquemin. Eshelby-Kröner viscoelastic self-consistent model: Multi-scale behavior of polymer composites under creep loading. Advanced Materials Research, 2013, 682, pp.105-112. 10.4028/www.scientific.net/AMR.682.105 . hal-01006807

\section{HAL Id: hal-01006807 \\ https://hal.science/hal-01006807}

Submitted on 2 Mar 2019

HAL is a multi-disciplinary open access archive for the deposit and dissemination of scientific research documents, whether they are published or not. The documents may come from teaching and research institutions in France or abroad, or from public or private research centers.
L'archive ouverte pluridisciplinaire HAL, est destinée au dépôt et à la diffusion de documents scientifiques de niveau recherche, publiés ou non, émanant des établissements d'enseignement et de recherche français ou étrangers, des laboratoires publics ou privés. 


\title{
Eshelby-Kröner viscoelastic self-consistent model: Multi-scale behavior of polymer composites under creep loading
}

\author{
A. Yousfi ${ }^{1, a^{*}}$, S. Fréour ${ }^{2, b}$ and F. Jacquemin ${ }^{2, c}$ \\ ${ }^{1}$ Mechanical Laboratory, University Amar Télidji of Laghouat, Algeria \\ ${ }^{2}$ Institut de Recherche en Génie Civil et Mécanique (UMR CNRS 6183), \\ LUNAM Université - Université de Nantes - Centrale Nantes \\ CRTT, 37 Boulevard de l'Université, BP 406, 44602 Saint-Nazaire cedex, France \\ a*youahm@yahoo.fr, 'sylvain.freour@univ-nantes.fr, 'frederic.jacquemin@univ-nantes.fr
}

Keywords: Multi-scale, polymer composites, creep, viscoelastic self-consistent model.

\begin{abstract}
The mechanical response of the composite structure in T650-35/PMR-15 aged at different temperatures was studied numerically. The time-dependent internal stresses in the composite ply and its constituents were computed during the creep process. In order to predict the effective properties of PMR-15/T650-35 composite ply in the temperature range $\left[250-350^{\circ} \mathrm{C}\right]$, the timedependent mechanical properties of PMR-15 matrix determined experimentally [1], were considered. The mechanical properties of the fibers do not experience any change due to the aging process in such a temperature range $[2,3]$. In order to achieve the computations, the visco-elastic Eshelby Kröner self-consistent model was used.
\end{abstract}

\section{Introduction}

The thermal aging of polymers is a slow process occurring mainly on structural elements designed to experience mechanical loading, while being subjected to high temperatures for long periods. In many cases, matrix creep can occur. As the role of the matrices is essentially to deform and support stresses primarily in shear, it becomes then important to consider this particularity within a phenomenological modeling framework [4]. This context corresponds to the case of graphitepolyimide composites used in aerospace applications $[1,5]$. According to, for instance, references $[6,7]$, below the glass transition temperature of its polymer matrix, composite materials exhibit a linear or at least a weakly nonlinear mechanical behavior until the damage threshold is attained. However, it is not the case anymore at high temperatures (relative to the glass transition temperature of the matrix). Indeed, recent experimental investigations performed at high temperatures on polyimide matrix composites, have shown very strong discrepancies from the linear elastic behavior $[1,2,8]$. These nonlinearities can be explained by two main mechanisms coupled together: the visco-elastic behviour of the polyimide matrix subjected to long-term loading at high temperatures, on the one hand, and the effects related to thermal aging, on the other hand.

\section{Multi-scale Modeling of the Viscoelastic Behavior}

Viscoelasticity is the generalization of a dual behavior, simultaneously elastic and viscous. It is characteristic of creep, which reveals itself as the strain states evolves over time, whereas the mechanical load imposed on the structure is kept constant. The combination of a mechanical load and a relatively high temperature can yield such a visco-elastic behavior of polymer matrix reinforced composites. Indeed, a creep strain, generally increasing as a function of the time is added to the purely elastic strain. The resulting total strain $\varepsilon$ does not only depend on the initial applied stress $\sigma$. It also becomes a function of time $(\mathrm{t})$ and temperature $(\mathrm{T})$ : $\boldsymbol{\varepsilon}=\mathrm{f}(\boldsymbol{\sigma}, \mathrm{t}, \mathrm{T})$. Maxwell model with three parameters (often called the standard viscoelastic model) is useful to describe the viscoelastic response of amorphous polymers or elastomers. This model allows highlighting every 
feature observed in practice for these materials, at least qualitatively. Accordingly, in order to correctly reproduce the experimental data in the time space, one often uses the Maxwell viscoelastic model generalized to the order $\mathrm{n}$, also called Wiechert model. The viscoelastic modulus then follows a Prony series:

$$
Y\left(t, T_{g}\right)=Y_{\infty}+\sum_{i=1}^{N}\left(Y_{i-1}-Y_{i}\right) \exp \left(-\frac{t}{\tau_{i}}\right) .
$$

\subsection{Linear Viscoelasticity}

The thermodynamics of irreversible processes allows for expressing the constitutive laws for the behavior of linear viscoelastic materials. The theory developed in [9] leads to the most general forms, which are often summarized by the following convolution integrals:

$$
\begin{aligned}
& \varepsilon^{i}(x, t)=\int_{0}^{t} \mathbf{L}^{i^{-1}}\left(t-t^{\prime}\right) \frac{d \sigma^{i}\left(x, t^{\prime}\right)}{d t^{\prime}} d t^{\prime} \\
& \boldsymbol{\sigma}^{\mathbf{i}}(\mathbf{x}, \mathbf{t})=\int_{0}^{\mathbf{t}} \mathbf{L}^{\mathbf{i}}\left(\mathbf{t}-\mathbf{t}^{\prime}\right) \frac{\mathbf{d} \varepsilon\left(\mathbf{x}, \mathbf{t}^{\prime}\right)}{\mathbf{d t ^ { \prime }}} \mathbf{d t ^ { \prime }}
\end{aligned}
$$

Where $\boldsymbol{\sigma}$ is the stress tensor, $\mathbf{L}^{\mathbf{i}}(\mathbf{t})$ the viscoelastic stiffness tensor of the constituent noted by the superscript $\mathrm{i}$, while $\mathbf{L}^{\mathbf{i}^{-1}}(\mathbf{t})$ is the viscoelastic compliance. Although each component constituting the ply composite satisfies a differential Maxwell equation, the constitutive law providing the effective response of a composite ply is not Maxwellian because of the coupling existing between the elastic and inelastic part of the strain rate. This coupling comes from the mechanical interactions occurring between the plies constituents, which induce interface stresses. However, without loss of generality of the model, one can assume that the overall macroscopic response of a given ply, represented by the superscript I, also satisfies a viscoelastic constitutive law whose form is that of a Stieltjes convolution:

$$
\boldsymbol{\varepsilon}_{\mathbf{k l}}^{\mathbf{I}}=\left(\mathbf{L}^{\mathbf{I}^{-1}}(\mathbf{t}) * \boldsymbol{\sigma}^{\mathbf{I}}\right)_{\mathbf{k l}} \equiv \int_{-\infty}^{\mathbf{t}} \mathbf{L}_{\mathbf{k} \mathbf{I m n}}^{\mathbf{I}^{-1}}\left(\mathbf{t}-\mathbf{t}^{\prime}\right) \frac{\mathbf{d} \boldsymbol{\sigma}_{\mathbf{m n}}^{\mathbf{I}}\left(\mathbf{t}^{\prime}\right)}{\mathbf{d \mathbf { t } ^ { \prime }}} \mathbf{d \mathbf { t } ^ { \prime }}
$$

Where $\boldsymbol{\varepsilon}^{\mathbf{I}}$ and $\boldsymbol{\sigma}^{\mathbf{I}}$ are the macroscopic stress and strain tensors, respectively.

$\mathbf{L}^{\mathbf{I}^{-1}}(\mathbf{t})$ is the viscoelastic stiffness tensor of the composite ply.

\subsection{Self-Consistent viscoelastic Model}

The macroscopic visco-elastic stiffness tensor of the composite ply, appearing above in equation (4), is a priori unknown. In the present work, it will be calculated owing to a scale-transition homogenization model. As part of the calculation process, each constituent is considered as an inclusion immersed in the Homogeneous Equivalent Medium representing the effective behaviour of the composite ply. Eshelby-Kröner self-consistent model (see $[10,11]$ for a description in pure elasticity) will be extended in this study to the case of creep loads will be applied here. 
A traditional method used for modeling the viscoelastic behaviour of a material consists in transforming the integral equations associated to the problem by means of the Carson transform [12]. The Carson transform of a function or a tensor $\mathrm{f}(\mathrm{t})$ is defined as:

$$
\mathbf{f}(\mathbf{s})=\mathbf{s} \int_{0}^{\infty} \exp (-\mathbf{s . t}) . \mathbf{f}(\mathbf{t}) . \mathbf{d t} \text {. }
$$

The application of the Carson transform (5) to the so-called "Hill's average relations" [13] yields:

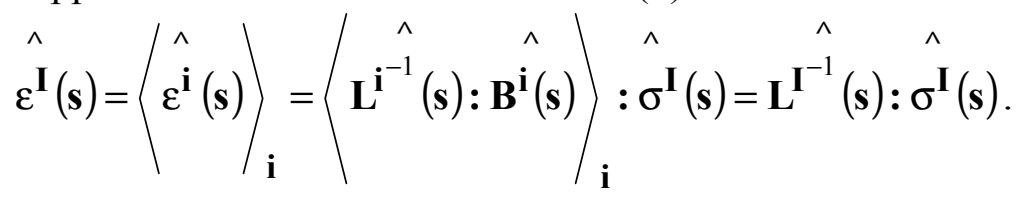

Where

$$
\mathbf{B}^{\mathbf{i}}(\mathbf{s})=\left[\hat{\mathbf{L}^{\mathbf{i}^{-1}}(\mathbf{s})+\mathbf{A}^{\mathbf{I}}(\mathbf{s}): \hat{\mathbf{L}}^{-1}(\mathbf{s})}\right]^{-1}:\left[\hat{\mathbf{L}^{-1}}(\mathbf{s})+\mathbf{A}^{\mathbf{I}}(\mathbf{s}): \hat{\mathbf{L}}^{\mathbf{I}^{-1}}(\mathbf{s})\right],
$$

is the stress concentration tensor expressed in the Carson transform space. $A^{I}(s)$ is the viscoelastic strain localization tensor expressed in the Carson transform space. This tensor relates the local pseudo-macroscopic strains experienced by a constituent to the corresponding macroscopic quantity:

$$
\mathbf{A}^{\mathbf{I}}(\mathbf{s})=\left(\mathbf{I}-\mathbf{E}^{\mathbf{I}}(\mathbf{s})\right)^{-1}: \mathbf{E}^{\mathbf{I}}(\mathbf{s})
$$

$\mathbf{E}^{\mathbf{I}}(\mathbf{s})$ is the transform of Eshelby's tensor and can be calculated in the general case of an ellipsoidal inclusion embedded in an anisotropic medium from the classical integral forms, provided that one replaces the elastic stiffness $\mathbf{L}_{\mathbf{e}}^{\mathbf{I}}$ by the corresponding creep stiffness, i.e. $\mathbf{L}^{\mathbf{I}}(\mathbf{s})$.

The comparison of expression (6) with the generic behavior law of the composite ply leads to an implicit equation to be satisfied by the macroscopic viscoelastic tensor:

$$
\mathbf{L}^{\mathbf{I}^{-1}}(\mathbf{s})=\left\langle\mathbf{L}^{\mathbf{i}^{-1}(\mathbf{s}): \mathbf{B}^{\mathbf{i}}(\mathbf{s})}\right\rangle_{\mathbf{i}} .
$$

\subsection{Viscoelastic Behaviour of the Polymer Matrix PMR-15}

The previously published contribution [1] reports the results of relaxation tests performed on samples made of pure PMR-15 polyimide resin. The relaxation tests were at four different temperatures: $275{ }^{\circ} \mathrm{C}, 300{ }^{\circ} \mathrm{C}, 325{ }^{\circ} \mathrm{C}, 350{ }^{\circ} \mathrm{C}$, during 2 hours. The time-dependent Young's modulus $\mathrm{Y}^{\mathrm{m}}(\mathrm{t})$ was deduced from these series of measurements by means of an optimization technique. The authors have found that the Young's modulus of PMR-15 matrix satisfies the following Prony series:

$$
\mathrm{Y}^{\mathrm{m}}(\mathrm{t})=\mathrm{Y}_{0}^{\mathrm{m}}+\mathrm{Y}_{1}^{\mathrm{m}} \exp \left(-\frac{\mathrm{t}}{\lambda_{1}^{\mathrm{m}}}\right)+\mathrm{Y}_{2}^{\mathrm{m}} \exp \left(-\frac{\mathrm{t}}{\lambda_{2}^{\mathrm{m}}}\right)
$$

where $\mathrm{Y}_{0}^{\mathrm{m}}, \mathrm{Y}_{1}^{\mathrm{m}}, \mathrm{Y}_{2}^{\mathrm{m}}, \lambda_{1}^{\mathrm{m}}$ et $\lambda_{2}^{\mathrm{m}}$ are unknown parameters. 


\section{Homogenization}

As suggested by the previously published work in this field of research, the time-dependent behaviour of the material should be described through a "sufficiently large" number of discrete calculations. Accordingly, a number $\mathrm{N}=500$ of points uniformly distributed on a logarithmic time scale between the initial stage $t=1 \mathrm{~s}$ and the final time $t_{\max }$ has been chosen. The resulting time step $t_{\text {step }}$ on the logarithmic scale would thus be given by the relation: $\quad t_{\text {step }}=\frac{\log t_{\max }}{N-1}$

In order to achieve the identification of the numerous components of the stiffness tensor, the following series of exponentials was used: $\quad \mathrm{L}_{11}^{\mathrm{m}}{ }^{-1}(\mathrm{t})=\sum_{\mathrm{p}=1}^{12} \mathrm{a}_{11}^{\mathrm{m}}(\mathrm{p}) \exp \left(-\lambda_{\mathrm{p}} . \mathrm{t}\right)$

A nonlinear least-squares fitting procedure was used in order to determine the 36 unknown coefficients $\mathrm{a}_{11}^{\mathrm{m}}(\mathrm{p}), \mathrm{a}_{12}^{\mathrm{m}}(\mathrm{p})$ et $\mathrm{a}_{44}(\mathrm{p})$ from the time-dependent evolution featured by the $\mathrm{N}=500$ discrete values of the stiffness components $\mathrm{L}_{11}^{\mathrm{m}}{ }^{-1}(\mathrm{t}), \mathrm{L}_{12}^{\mathrm{m}}{ }^{-1}(\mathrm{t})$ et $\mathrm{L}_{44}^{\mathrm{m}}{ }^{-1}(\mathrm{t})$ of the PMR-15 matrix assumed to remain isotropic in the viscoelastic regime. This approach provides an analytical form for the Carson transform of the time-dependent evolution of each component. Thus, for example, one would easily write: $\quad \mathrm{L}_{11}^{-1}(\mathrm{~s})=\mathrm{s} \int_{0}^{\infty} \exp (-\mathrm{s} . \mathrm{t}) \mathrm{L}_{11}^{\mathrm{m}^{-1}}(\mathrm{t}) \mathrm{dt}=\mathrm{s} \sum_{\mathrm{p}=1}^{12} \frac{\mathrm{a}_{11}(\mathrm{p})}{1+\frac{\mathrm{s}}{\lambda_{\mathrm{p}}}}$.

The procedure is even more straightforward for the carbon fiber, assuming that the stiffness tensor of this constituent is independent of time. Accordingly the following relation holds:

$\mathbf{L}^{\mathbf{f}}(\mathbf{t})=\mathbf{L}_{\mathbf{e}}^{\mathbf{f}}=\mathbf{L}^{\mathbf{f}}(\mathbf{s})$. The properties considered for the T650-35 graphite fibers are summarized in Table 1 below:

Table 1: Thermo-elastic properties of the fiber T650-35 from Rupnowski [2, 3].

\begin{tabular}{lcccccc}
$\mathrm{E}_{\mathrm{fL}}[\mathrm{GPa}]$ & $\mathrm{E}_{\mathrm{fT}}[\mathrm{GPa}]$ & $\mathrm{G}_{\mathrm{fL}}[\mathrm{GPa}]$ & $\mathrm{G}_{\mathrm{fT}}[\mathrm{GPa}]$ & $v_{\mathrm{fL}}$ & $\alpha_{\mathrm{fL}}\left[10^{-6} /{ }^{\circ} \mathrm{C}\right]$ & $\alpha_{\mathrm{fT}}\left[10^{-6} /{ }^{\circ} \mathrm{C}\right]$ \\
\hline $224 \pm 3$ & $15.4 \pm 0.5$ & $21.1 \pm 1.1$ & $5.8 \pm 0.4$ & $0.44 \pm 0.02$ & $1.2 \pm 0.05$ & $13.5 \pm 0.8$ \\
\hline
\end{tabular}

For each value of $s(n)=\frac{1}{t(n)}$, an initial value of the macroscopic viscoelastic stiffness tensor expressed in the Carson transform space is estimated, using the following simplified model historically established in pure elasticity [14]:

$$
\begin{array}{ll}
Y_{1, \text { ini }}^{\mathrm{I}}(\mathrm{s})=v^{\mathrm{m}} \mathrm{Y}_{1}^{\mathrm{m}}(\mathrm{s})+\mathrm{v}^{\mathrm{f}} \mathrm{Y}_{1}^{\mathrm{f}}(\mathrm{s}), & \mathrm{Y}_{2, \text { ini }}^{\mathrm{I}}(\mathrm{s})=\left[\frac{\mathrm{v}^{\mathrm{m}}}{\mathrm{Y}_{1}^{\mathrm{m}}(\mathrm{s})}+\frac{\mathrm{v}^{\mathrm{f}}}{\mathrm{Y}_{2}^{\mathrm{f}}(\mathrm{s})}\right]^{-1}, \\
v_{12, \text { ini }}^{\mathrm{I}}(\mathrm{s})=\mathrm{v}^{\mathrm{m}} v^{\mathrm{m}}(\mathrm{s})+\mathrm{v}^{\mathrm{f}} v_{12}^{\mathrm{f}}(\mathrm{s}), & v_{23, \text { ini }}^{\mathrm{I}}(\mathrm{s})=\mathrm{v}^{\mathrm{m}} v^{\mathrm{m}}(\mathrm{s}) \mathrm{Y}_{2}^{\mathrm{f}}(\mathrm{s})+\mathrm{v}^{\mathrm{f}} v_{23}^{\mathrm{f}}(\mathrm{s}) \mathrm{Y}_{2}^{\mathrm{m}}(\mathrm{s}), \\
\mathrm{G}_{12, \text { ini }}^{\mathrm{I}}(\mathrm{s})=\left[\frac{\mathrm{v}^{\mathrm{m}}}{\mathrm{G}^{\mathrm{m}}(\mathrm{s})}+\frac{\mathrm{v}^{\mathrm{f}}}{\mathrm{G}_{12}^{\mathrm{f}}(\mathrm{s})}\right]^{-1} . &
\end{array}
$$

The initial macroscopic compliance tensor $\mathbf{L}_{\text {ini }}^{\mathbf{I}^{-1}}(\mathbf{s})$ in the Carson transform space is primarily evaluated for each of the $\mathrm{N}=500$ discrete $\mathrm{s}(\mathrm{n})$ values considered. Then the self-consistent approach is applied, in order to determine iteratively the effective macroscopic compliance tensor $\mathbf{L}^{\mathbf{I}^{-1}}(\mathbf{s})$ in Carson transform space. It is assumed that each component of the macroscopic stiffness tensor 
expressed in the Carson transform space satisfies a Dirichlet finite series of 12 terms similar to that defined above for the components of the composite ply. As a consequence, it is necessary to use a numerical optimization method in order to find the 12 constant coefficients defining the evolution, in the Carson transform space for each of the six components of the macroscopic viscoelastic tensor. Then, the inverse Laplace transform is applied to the found Dirichlet series in order to obtain the time-dependent evolution of the macroscopic stiffness tensor.

Following a similar method, one can determine the time-dependent evolution of the coefficients of thermal and/or hygroscopic expansion. In the first case, for example, the following homogenization relation should be applied instead of (8) in order to determine a discrete value of the coefficient of thermal expansion macroscopic $\alpha^{\mathrm{I}}$ in the Carson transform space:

$$
\alpha^{\mathbf{I}}(\mathbf{s})=\mathbf{L}^{\mathbf{I}^{-1}}(\mathbf{s}):\left\langle\left[\mathbf{E}^{\mathbf{I}}(\mathbf{s}):\left(\mathbf{L}^{\mathbf{i}}(\mathbf{s})-\mathbf{L}^{\mathbf{I}}(\mathbf{s})\right)+\mathbf{I}\right]^{-1}: \mathbf{L}^{\mathbf{i}}(\mathbf{s}): \alpha^{\mathbf{i}}(\mathbf{s}) \Delta \mathbf{T}\right\rangle
$$

The time-dependent evolution of the macroscopic coefficients of thermal expansion and/or their hygroscopic counterparts is determined through a method similar to the procedure described above for the macroscopic viscoelastic stiffness tensor.

\section{Results and Discussion}

Figure 1a shows the evolutions of the visco-elastic modulus $\mathrm{Y}^{\mathrm{m}}$ of the pure PMR-15 matrix as a function of time and temperature. The elastic modulus of the studied polymer decreases during the creep process. Besides a strong evolution of $\mathrm{Y}^{\mathrm{m}}$, as a function of the temperature, is observed. The stiffness decreases from the value corresponding to the elastic behaviour at the initial stage but eventually reaches a constant, asymptotic value in the permanent regime. In between, a transient stage occurs where the visco-elastic modulus changes continuously.
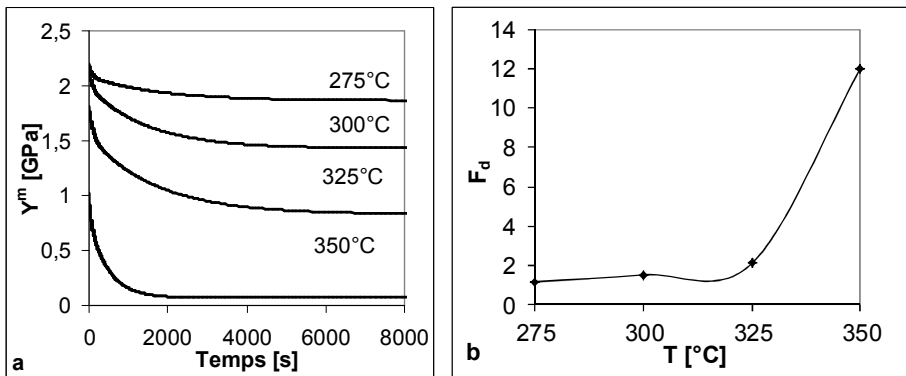

Fig 1: (a) Young's modulus of the matrix $\mathrm{Y}^{\mathrm{m}}$ PMR-15 as a function of time. (b) The decrease factor of Young's modulus, for different creep temperatures.

The duration of this transient stage decreases as the applied temperature increases. The asymptotic creep modulus dramatically falls from its reference elastic counterpart as the temperature increases as shown on figure $1 \mathrm{~b}$. According to that curve, at $\mathrm{T}=350^{\circ} \mathrm{C}$, the Young's modulus is experiences a division by as much as 12 , for instance.
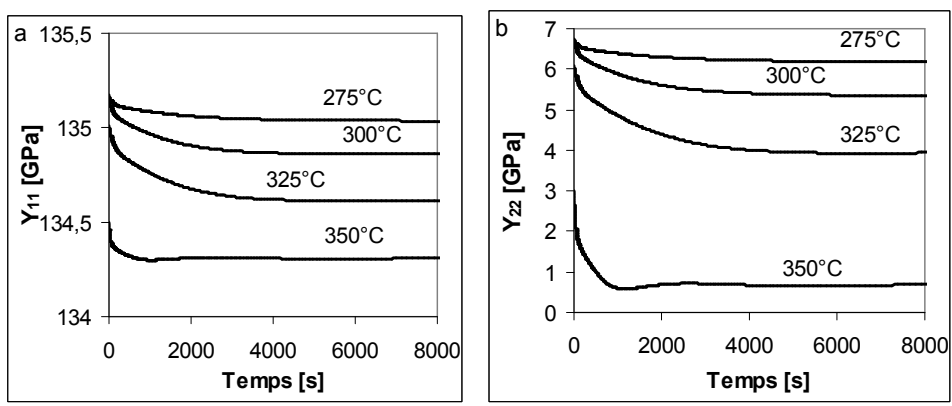

Fig 2: The effective longitudinal modulus $\left(\mathrm{Y}_{11}\right)(\mathrm{a})$ and transverse $\left(\mathrm{Y}_{22}\right)$ (b) predicted as a function of time for the composite ply PMR-15/T650-35, at different creep temperatures.

Figures (2-6) show the effective hygro-thermo-mechanical properties for a unidirectional composite ply PMR-15/T650-35 containing 60\% fiber volume, submitted to creep conditions, calculated as a function of time using Eshelby-Kröner self-consistent model. The numerical predictions of the 
macroscopic longitudinal and transverse Young's moduli are shown in figures $2 \mathrm{a}$ and $2 \mathrm{~b}$ respectively, whereas the longitudinal and transverse shear moduli are shown in figures $3 \mathrm{a}$ and $3 \mathrm{~b}$. The transverse Young's modulus $\mathrm{Y}_{22}$ and shear moduli $\mathrm{G}_{23}$ drop by a factor of two during the relaxation process for the creep temperature $\mathrm{T}=350{ }^{\circ} \mathrm{C}$.

Conversely, the longitudinal Young's modulus of a macroscopic ply composite reinforced with parallel fibers is not significantly modified by the softening of the organic matrix. The keeping of such high properties in the longitudinal direction should ensure the durability of composite parts made of PMR-15/T650-35, intended to undergo this type of loading during their service life. As for the macroscopic shear plane modulus $\left(\mathrm{G}_{12}\right)$, it is reduced when the material is placed under creep conditions, but the weakening observed for this module, while not negligible, is intermediate between what is observed for longitudinal and transverse Young's moduli.
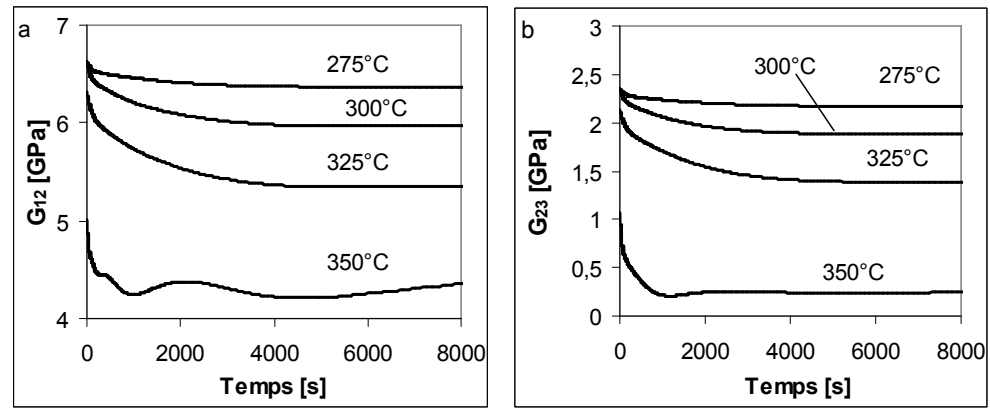

Fig 3: The effective shear moduli $\left(\mathrm{G}_{12}\right)(\mathrm{a})$ and $\left(\mathrm{G}_{23}\right)(\mathrm{b})$ predicted as a function of time for the composite ply PMR-15/T650-35, at different creep temperatures.

Since both the thermal and hygroscopic properties of the matrix may vary under creep conditions. Consequently, the corresponding macroscopic thermal and hygroscopic properties will be affected, also. The macroscopic coefficients of expansion predicted by Eshelby-Kröner self-consistent model are shown on figures 4, 5 and 6. The macroscopic coefficient of thermal expansion was calculated from three independent sets of constituents properties fort the polymer matrix: its coefficients of thermal expansion were assumed (a) to be constant (see figures 4a-5a); (b) to follow the behavior law observed in practice by Rupnowski et al. [2] (see Figures 4b-5b) and (c) behavior law described by Benedikt et al. [15] (see figures 4c, 5c)). Figures 4c and 5c highlight the effect of viscoelasticity on the macroscopic coefficients of thermal expansion $\left(\alpha_{11}\right.$ and $\left.\alpha_{22}\right)$, the latter decreasing during relaxation. From the time $\mathrm{t}=4000 \mathrm{~s}$ the CTE reaches an asymptotic value corresponding to a fall of around $15 \%$ in relative value. It is noticeable, however, that the effective macroscopic coefficient of thermal expansion in the direction parallel to the reinforcing fibers remains almost constant throughout the creep process. The magnitude of the variations calculated for $\alpha_{11}$ stay below 5.10${ }^{7} / \mathrm{K}$. This result should be attributed to the small influence of the properties of the polymer matrix on the effective behavior of the bulk material in this specific direction.
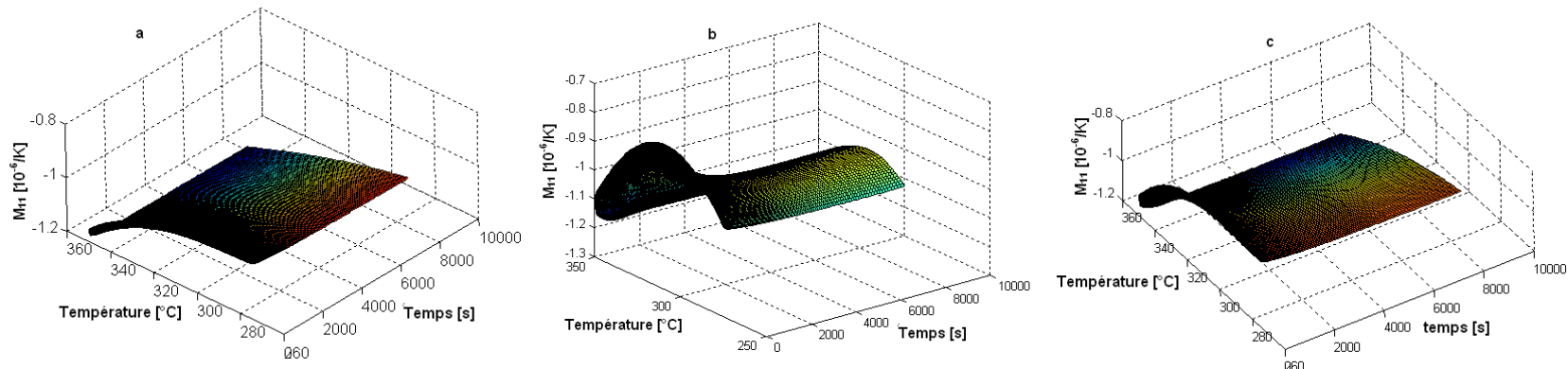

Fig 4: The effective coefficients of thermal expansion $\left(\alpha_{11}\right)$, as a function of time, the composite ply PMR-15/T650-35 for different temperatures creep. (a) the CTE of the matrix is constant, (b) the CTE of the matrix follows the law described by Rupnowski [2], (c) the CTE of the matrix follows the law described by Benedikt [15].

According to figure 5, the effective coefficients of thermal expansion predicted for the composite plies do strongly depend on the corresponding values taken from the literature for the PMR-15 
matrix (see $[2,15]$ ). The differences between the curves displayed on figures $5 \mathrm{a}, 5 \mathrm{~b}$ and $5 \mathrm{c}$ precisely come from the variability of experimental data sets available for the considered organic matrix. The magnitude of the effective properties remains similar, however.

As a result, the overall shape of the $3 \mathrm{D}$ evolutions of the macroscopic transverse coefficient of thermal expansion, as a function of both the time and the temperature looks rather similar, whatever the organic matrix properties accounted for.
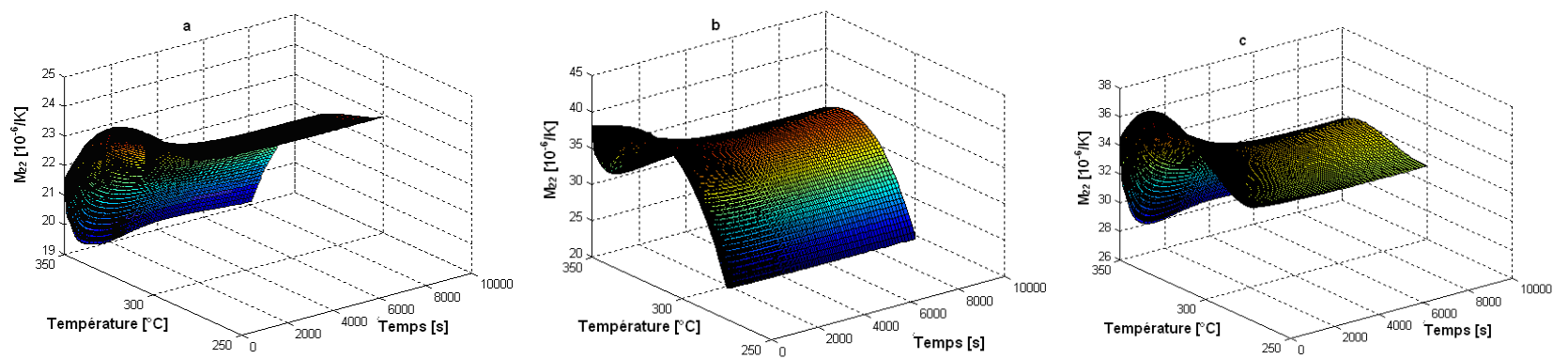

Fig 5: The effective coefficients of thermal expansion $\left(\alpha_{22}\right)$, as a function of time, the composite ply PMR-15/T650-35 for different temperatures creep. (a) the CTE of the matrix is constant, (b) the CTE of the matrix follows the law described by Rupnowski [2], (c) the CTE of the matrix follows the law described by Benedikt [15].

The predicted coefficients of moisture expansion are shown on figure 6 . The effects induced by a creep load on the macroscopic Coefficients of Moisture Expansion $\left(\beta_{11}\right.$ and $\left.\beta_{22}\right)$ are similar to those described above in the case that the coefficients of thermal expansion were investigated. Both $\beta_{11}$ and $\beta_{22}$ decrease during the relaxation of the composite ply. In the studied creep conditions, the model predicts a decrease over the time of the Coefficients of Moisture Expansion for around 1 hour before an asymptotic value is reached. Relative changes of these coefficients are larger than those experienced by the coefficients of thermal expansion. For example, at $\mathrm{T}=350{ }^{\circ} \mathrm{C}$, the model predicts a relative variation that can attain as much as $40 \%$ for the component $\beta_{22}$. The variations for the hygroscopic expansion coefficient parallel to the reinforcing fibers are not significant, in the sense that the absolute value of this quantity is always low (and close to zero) in the whole time/temperature range of the studied domain.
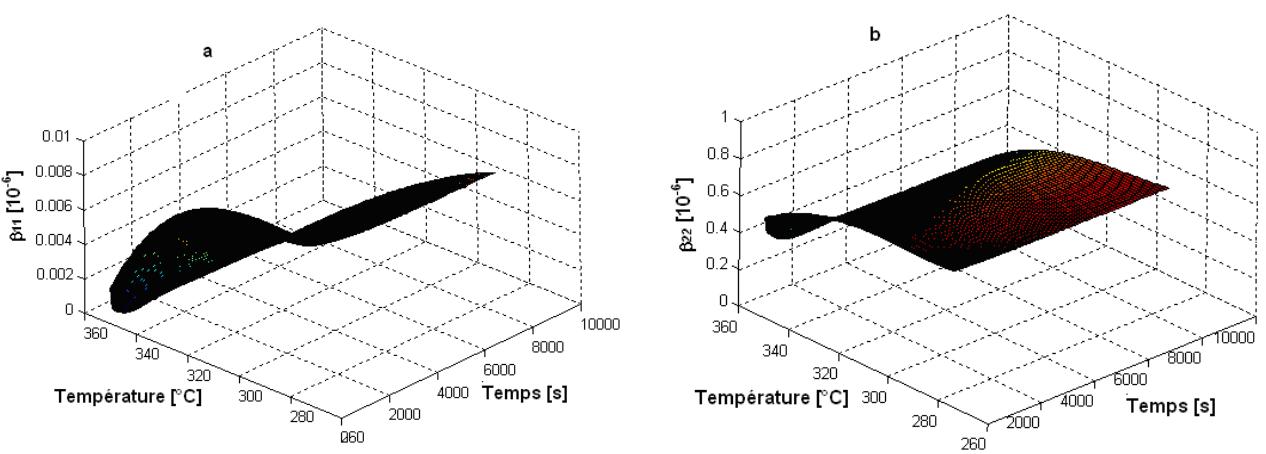

Fig 6: The effective coefficients of hygroscopic expansion $\left(\beta_{11}\right)(a)$ and $\left(\beta_{22}\right)(b)$, as a function of time, the composite ply PMR-15/T650-35 for different temperatures creep.

\section{Conclusion}

This study is devoted to the durability of organic matrix composites reinforced with unidirectional long fibers. The effect of thermal aging on the effective mechanical behavior of composite plies PMR-15/T650-35 subjected to creep conditions at high temperatures $\left(\mathrm{T}=275{ }^{\circ} \mathrm{C}-350{ }^{\circ} \mathrm{C}\right)$ was investigated. The macroscopic hygro-thermo-mechanical properties were evaluated numerically using the viscoelastic Eshelby-Kröner self-consistent scale transition model. In the longitudinal direction (parallel to the reinforcing fibers), the model predicts that the effective properties of the 
studied material are not affected by the softening of the organic matrix that constitutes the composite plies. This should ensure the reliability of the structural parts submiotted to such thermomechanical loads. In the transverse directions to the reinforcing fibers, the macroscopic properties (Young's modulus, as well as the coefficients of thermal expansion and hygroscopic expansion) undergo a significant reduction during the creep process. This decrease could modify the distribution of the multi-scale mechanical states within the components of the plies. As a result, the durability of the composite parts could be impaired. The results obtained in the present work will feed further investigations focused on the multi-scale mechanical states experienced by structures made from unidirectional composites plies PMR-15/T650-35 submitted to creep conditions.

\section{References}

[1] P. Rupnowski, M. Gentz, D. Armentrpout, J. K. Sutter and M. Kumosa: The response of a woven graphite fiber/polyimide composite to aging in nitrogen. Acta Materialia, 53, (2005), 4555-4565.

[2] P. Rupnowski, M. Gentz, J.K. Sutter and M. Kumosa: Mechanical response of a woven graphite/polyimide composite to in-plane shear dominated loads at room and elevated temperatures. Acta Materialia, 52, (2004), 5603-5613.

[3] P. Rupnowski, M. Gentz, J. K. Sutter and M. Kumosa: An evaluation of elastic properties and thermal expansion coefficients of medium and high modulus graphite fibers. Composites Part A, 36, (2005-b), 327-338.

[4] B. Nedjar, A time dependent model for unidirectional fibre-reinforced composites with viscoelastic matrices. International Journal of Solids and Structures 48, (2011) 2333-2339.

[5] D. Wilson: Recent advances in polyimide composites. High Performance Polymers 5(2), (1993), 77-95.

[6] P.D. Soden, M.J. Hinton, and A. S. Kaddour: Experimental failure stresses and deformations for a range of composite laminates subjected to uniaxial and biaxial loads. Composite Science and Technology, 62, (2002), 1489-514.

[7] A.S. Kaddour, M.J. Hinton and P.D. Soden: Behaviour of $\pm 45^{\circ}$ glass/epoxy filament wound composite tubes under quasi-static equal biaxial tension-compression loading: experimental results. Composites: Part B, 34, (2003), 689-704.

[8] B. Benedikt, M. Lewis, P. Rangaswamy, M. Kumosa, P. Predecki, L. Kumosa and M. Gentz: Residual stress analysis in aged graphite/PMR-15 composites using X-Ray diffraction. Materials Science and Engineering A, 421, (2006), 1-8.

[9] M.A. Biot: Theroy of stress-strain relations in anisotropic viscoelasticity and relaxation phenomena. J. Appl. Phys., 25, (1954), 1385-1391.

[10] F. Jacquemin, S. Fréour and R. Guillén: A Hygroelastic Self-consistent Model for Fiberreinforced Composites. Journal of Reinforced Plastics and Composites, 24, (2005), 485-502.

[11] S. Fréour, F. Jacquemin and R. Guillén: On an analytical Self-Consistent model for internal stress prediction in fiber-reinforced composites submitted to hygro-elastic load. Journal of Reinforced Plastics and Composites, 24, (2005), 1365-1377.

[12] C. Cruz, J. Diani and G. Régnier, Micromechanical modelling of the viscoelastic behaviour of an amorphous poly(ethylene)terephthalate (PET) reinforced by spherical glass beads, Composites Part A: Applied Science and Manufacturing, 40, 6-7, (2009), 695-701.

[13] R. Hill: The elastic behaviour of a crystalline aggregate. Proceedings of the Physical Society, 65(1952), 349-354.

[14] C.T. Herakovitch: Mechanics of Fibrous Composites. John Wiley and Sons Inc., New York, (1998).

[15] B. Benedikt, M. Gentz, L. Kumosa, P. Rupnowski, J.K. Sutter, P.K. Predecki, and M. Kumosa: $\mathrm{X}$-ray diffraction experiments on aged graphite fiber/polyimide composites with embedded aluminum inclusions. Composites: Part A, 35, (2004), 667-681. 